\title{
Key Acronyms
}

$\begin{array}{ll}\text { APO } & \text { Ausserparlamentarische Opposition } \\ \text { CDU } & \text { Christlich Demokratische Union Deutschlands } \\ \text { DDR } & \text { Deutsche Demokratische Republik ("East Germany") } \\ \text { J2M } & \text { June 2 Movement (2. Juni Bewegung) } \\ \text { KPD } & \text { Kommunistische Partei Deutschlands } \\ \text { LNS } & \text { Liberation News Service } \\ \text { NLF } & \text { National Liberation Front (Vietnam) } \\ \text { NYT } & \text { New York Times } \\ \text { PFOCs } & \text { Prairie Fire Organizing Committees } \\ \text { PL } & \text { Progressive Labor [Party] } \\ \text { PLO } & \text { Palestine Liberation Organization } \\ \text { RAF } & \text { Rote Armee Fraktion [Red Army Faction] } \\ \text { RYM } & \text { Revolutionary Youth Movement } \\ \text { SDS } & \text { Sozialistischer Deutscher Studentenbund } \\ \text { SDS } & \text { Students for a Democratic Society } \\ \text { SLA } & \text { Symbionese Liberation Army } \\ \text { SPD } & \text { Sozialdemokratische Partei Deutschland } \\ \text { UCB } & \text { University of California at Berkeley } \\ \text { WP } & \text { Washington Post } \\ \text { WUO } & \text { Weather Underground Organization }\end{array}$


This page intentionally left blank 